\title{
Benign familial hyperphosphatasaemia as a cause of unexplained increase in plasma alkaline phosphatase activity
}

\author{
S B Rosalki, A Y Foo, J S Dooley
}

\begin{abstract}
Aims-To consider a possible genetic origin for the persistent unexplained increase in plasma alkaline phosphatase (ALP) in five non-related patients referred over an 18 month period. Methods-Plasma ALP isoenzyme activities were measured in patients and their first degree relatives.

Results-In each patient there was a noticeable increase in intestinal plasma ALP, either alone or accompanied by an increase in bone or liver ALP. Family studies showed an unexpected increase in plasma ALP and similar isoenzyme changes in first degree relatives. The findings were consistent with autosomal dominant inheritance.

Conclusion-Inherited raised plasma ALP activity is a reasonably common cause of persistent unexplained hyperphosphatasaemia which deserves wider recognition.
\end{abstract}

( Clin Pathol 1993;46:738-741)

A persistent increase in plasma alkaline phosphatase (Orthophosphoric monoester phosphohydrolase (alkaline optimum) EC $3 \cdot 1 \cdot 3 \cdot 1$; ALP) in the absence of clinical evidence of disease is most often a consequence of occult bone or liver disorder. This is generally indicated by the appropriate biochemical, radiological, scintigraphic, or biopsy investigations. Despite this, there are some patients who show no other abnormality for whom measurement of plasma ALP isoenzymes, preferably by electrophoresis, is mandatory. This may show an increase in bone or liver fraction, but, sometimes, an unexpected increase in intestinal origin phosphatase may also be found. This persists in fasting samples. A raised intestinal fraction is well recognised in association with hepatic cirrhosis, ${ }^{1}$ chronic renal failure, ${ }^{2}$ or diabetes mellitus, ${ }^{3}$ but the possibility of a genetic origin is frequently overlooked. ${ }^{4}$ It is our practice to recommend family studies whenever a persistent increase in the intestinal fraction is found in the absence of the above disorders. Consequently, when first degree relatives were available for study, we were able to show the presence of an inherited hyperphosphatasaemia in several such patients.

\section{Methods}

Fasting samples were requested from all family members. Total ALP activity was measured in accordance with the International Federation of Clinical Chemistry (IFCC) recommendations, but at $37^{\circ} \mathrm{C} .^{5} \mathrm{ALP}$ isoenzymes were separated and quantified by wheat germ lectin affinity electrophoresis with densitometric scanning. ${ }^{6}$ Liver and bone ALP migrated in the $a_{2}$-globulin position. ALP migrating in the $\beta$-globulin position was confirmed as intestinal by retardation after preincubation with specific monoclonal antibody. Intestinal-variant $\mathrm{ALP}^{7}$ was shown as activity remaining in the $a_{2}$-globulin region after prolonged sample preincubation with neuraminidase. ${ }^{8}$

Our upper reference limits in adults are $130 \mathrm{IU} / 1$ for total ALP, $60 \mathrm{IU} / 1$ for liver ALP, $70 \mathrm{IU} / 1$ for bone ALP and $20 \mathrm{IU} / 1$ for intestinal ALP, independent of blood group. The detection limit of the electrophoretic method is less than $5 \mathrm{IU} / 1$

Five families were studied.

FAMILY 1

The propositus (JP) was a 30 year old woman with a persistent, unexplained, increase in plasma ALP of about two and a half times the upper reference limit. Isoenzyme electrophoresis showed a mild increase in the liver ALP fraction together with a substantial increase in the intestinal isoenzyme, confirmed by retardation of mobility following incubation with anti-intestinal ALP monoclonal antibody. Because of the increase in intestinal ALP, family studies were advised. The father and mother were both clinically normal, but both showed raised total ALP activity. In the father there was a mild increase in total ALP and in the liver fraction, borderline bone isoenzyme activity, and an increased intestinal fraction. ALP of slow $a_{1}$ mobility ("slow $a_{1}$-ALP"), just anodal to liver ALP, was also detected. The mother also showed raised total ALP activity, with an increase in the liver fraction. Results are shown in table 1 .

FAMILY 2

The propositus case (sample referred by $\mathrm{Dr}$ D Donaldson, East Surrey Hospital) was a young soldier, aged 21 , who on three occasions had been found to have raised ALP activity, of about three times the upper reference limit. There was no other abnormality 
Table 1 Plasma alkaline phosphatase total and isoenzyme activity in patients and their family members

\begin{tabular}{|c|c|c|c|c|c|c|}
\hline & Age & $\begin{array}{l}\text { Total } A L P \\
(\times U R L)\end{array}$ & Slow $\alpha_{1}$ & $\begin{array}{l}\text { Liver } \\
(\times U R L)\end{array}$ & $\begin{array}{l}\text { Bone } \\
(\times U R L)\end{array}$ & $\begin{array}{l}\text { Intestinal } \\
(\times \cup R L)\end{array}$ \\
\hline $\begin{array}{c}\text { Family } 1 \\
\text { Patient, F } \\
\text { Father } \\
\text { Mother }\end{array}$ & 30 & $\begin{array}{l}2.4 \\
1.5 \\
1.2\end{array}$ & $\begin{array}{l}\text { ND } \\
\text { Present } \\
\text { ND }\end{array}$ & $\begin{array}{l}1.3 \\
1.3 \\
1.5\end{array}$ & $\begin{array}{l}0.6 \\
1.0 \\
0.9\end{array}$ & $\begin{array}{r}9 \cdot 0 \\
1.6 \\
\mathrm{ND}\end{array}$ \\
\hline $\begin{array}{l}\text { Family } 2 \\
\text { Patient, } M \\
\text { Father } \\
\text { Mother } \\
\text { Brother }\end{array}$ & $\begin{array}{l}21 \\
80 \\
51 \\
23\end{array}$ & $\begin{array}{l}2 \cdot 4 \\
0.9 \\
0 \cdot 8 \\
0.9\end{array}$ & $\begin{array}{l}\text { Present } \\
\text { ND } \\
\text { Present } \\
\text { ND }\end{array}$ & $\begin{array}{l}1 \cdot 0 \\
1.0 \\
0 \cdot 6 \\
0.7\end{array}$ & $\begin{array}{l}0.5 \\
0.7 \\
0.4 \\
0.7\end{array}$ & $\begin{array}{r}11.6 \\
0.3 \\
1.9 \\
1.1\end{array}$ \\
\hline $\begin{array}{l}\text { Family } 3 \\
\text { Patient, F } \\
\text { Daughter } 1 \\
\\
\\
\text { Son }\end{array}$ & $\begin{array}{l}53 \\
28 \\
26 \\
24 \\
27\end{array}$ & $\begin{array}{l}2 \cdot 4 \\
0.9 \\
0 \cdot 7 \\
0 \cdot 8 \\
1.0\end{array}$ & $\begin{array}{l}\text { Present } \\
\text { ND } \\
\text { ND } \\
\text { ND } \\
\text { ND }\end{array}$ & $\begin{array}{l}1 \cdot 2 \\
0.7 \\
0.4 \\
0.4 \\
0.9\end{array}$ & $\begin{array}{l}0.9 \\
0.3 \\
0.7 \\
0.9 \\
0.7\end{array}$ & $\begin{array}{l}8 \cdot 6 \\
2 \cdot 2 \\
0 \cdot 6 \\
0 \cdot 5 \\
1 \cdot 2\end{array}$ \\
\hline $\begin{array}{l}\text { Family } 4 \\
\text { Patient, F } \\
\text { Daughter } 1 \\
\\
\text { Son } 1 \\
2 \\
\text { Sister } 1 \\
2\end{array}$ & $\begin{array}{l}55 \\
22 \\
25 \\
23 \\
27 \\
69 \\
66\end{array}$ & $\begin{array}{l}2 \cdot 1 \\
1 \cdot 0 \\
0 \cdot 8 \\
1 \cdot 7 \\
1 \cdot 0 \\
2 \cdot 0 \\
3 \cdot 1\end{array}$ & $\begin{array}{l}\text { Present } \\
\text { ND } \\
\text { ND } \\
\text { ND } \\
\text { ND } \\
\text { ND } \\
\text { ND }\end{array}$ & $\begin{array}{l}1.4 \\
0.5 \\
0.6 \\
1.4 \\
0.8 \\
1.2 \\
1.5\end{array}$ & $\begin{array}{l}2 \cdot 0 \\
1.3 \\
0.7 \\
1.4 \\
0.7 \\
2.5 \\
2 \cdot 2\end{array}$ & $\begin{array}{c}2.5 \\
\text { ND } \\
\text { ND } \\
0.9 \\
\text { ND } \\
\text { ND } \\
3.8\end{array}$ \\
\hline $\begin{array}{l}\text { Family } 5 \\
\text { Patient, M } \\
\text { Mother } \\
\text { Sister } \\
\text { Half-sister }\end{array}$ & $\begin{array}{l}44 \\
66 \\
41 \\
31\end{array}$ & $\begin{array}{l}3 \cdot 6 \\
1 \cdot 2 \\
3 \cdot 1 \\
1 \cdot 0\end{array}$ & $\begin{array}{l}\text { Present } \\
\text { ND } \\
\text { Present } \\
\text { ND }\end{array}$ & $\begin{array}{l}1.4 \\
0.9 \\
1.2 \\
0.9\end{array}$ & $\begin{array}{l}2.9 \\
1 \cdot 1 \\
1.7 \\
1.0\end{array}$ & $\begin{array}{c}6 \cdot 9 \\
0 \cdot 8 \\
9 \cdot 2 \\
\text { ND }\end{array}$ \\
\hline
\end{tabular}

Results are expressed as multiples of the respective upper reference limits (URL). The presence or absence of ALP activity in the slow $a_{1}$ region on electrophoresis is also indicated. ND $=$ not detected. $\mathrm{F}=$ female, $M=$ male.

apart from a mild increase in plamsa bilirubin which varied between 29 and $39 \mu \mathrm{mol} / 1$, and which was diagnosed as being due to Gilbert's disease. Isoenzyme examination showed normal liver and bone fractions but the intestinal fraction was substantially increased and accounted for most of the ALP activity. ALP in the slow $a_{1}$-position was also present. Family studies were suggested, and specimens were obtained from both parents and an older brother. Both parents showed normal total ALP activity and normal bilirubin values. Liver, bone, and intestinal ALP were detectable in the plasma of the father but none of these fractions was increased. In the mother, however, the intestinal fraction was substantially increased and staining in the slow $a_{1}$-position was seen. In the brother liver and bone ALP were both present at normal activity, together with a borderline intestinal ALP fraction. Results are shown in table 1.

FAMILY 3

A 53 year old woman with persistent unexplained hyperphosphatasaemia - total activity about two and a half times the upper reference limit-had a slight increase in the liver fraction by isoenzyme electrophoresis together with a pronounced increase in intestinal ALP, the latter accounting for more than $50 \%$ of total ALP activity. ALP in the slow $a_{1}$-region was also present. Pre-incubation with anti-intestinal monoclonal antibody retarded the mobility of the intestinal fraction with accompanying disappearance of the slow $\alpha_{1}$-band, possibly because of its retardation and incorporation within liver ALP. A sample was obtained from her daughter, aged 28 . This also showed increased intestinal ALP, accounting for $40 \%$ of her total ALP.
Samples from two other daughters, aged 26 and 24, showed normal total ALP and isoenzyme values. A son aged 27 , however, had a borderline total value, with a barely increased intestinal ALP value (table 1). Intestinal-variant ALP was shown in the $a_{2}$ globulin region after prolonged treatment with neuraminidase of samples from the patient, the eldest daughter, and the son.

FAMILY 4

A 55 year old woman without any clinical symptoms had shown a persistent increase in ALP over a two year period. Isoenzyme examination of the patient's plasma at St James's Hospital, Leeds (Dr RB Payne) had shown high ALP activity in the intestinal position and the sample was referred for confirmation. ALP activity was about twice the upper reference limit of normal and the sample showed increased activity of liver, bone, and intestinal phosphatase, together with some staining in the slow $a_{1}$-region. Preincubation with anti-intestinal ALP monoclonal antibody produced changes similar to that seen in the propositus case of family 3. A possible genetic abnormality was suggested and samples from two sisters, two sons, and two daughters were forwarded for examination. An elder sister aged 69 had ALP activity about four times the upper reference limit with an increased bone fraction. A second sister aged 66 had a total ALP value about two and a half times the upper reference limit, together with increased liver, bone, and intestinal ALP. Intestinal-variant ALP activity was detected in this plasma following prolonged pre-incubation with neuraminidase. A 23 year old son had total ALP activity about one and a half times the upper reference limit, with increased liver and bone fractions and borderline intestinal ALP activity. A 22 year old daughter had total ALP activity at the upper reference limit of normal with a raised bone fraction. Two other children, a daughter aged 25 and a son aged 27 , had normal total activity and isoenzyme distribution (table 1). ALP isoenzyme electrophoretic patterns on various family members are shown in the figure.

FAMILY 5

A 44 year old man had had unexplained raised ALP activity for three years. He was overweight and hypertensive; his total ALP activity was noted (Dr J Went, Derriford Hospital, Plymouth) to be about three and a half times the upper reference limit, with the presence of intestinal isoenzyme. We found an increase in the liver, bone, and intestinal fractions, together with two faint-staining bands just in advance of the liver fraction in the slow $a_{1}$ position. These and the intestinal fraction showed the same response to preincubation with anti-intestinal ALP monoclonal antibody as that noticed in the two previous families. Specimens were made available from the patient's mother, sister, and half-sister (same mother, different father). The mother, aged 66, had mildly 
Plasma ALP isoenzyme patterns from family 4. The patient (track 2) and his sister (track 3) show increased total, liver (L), bone $(B)$, and intestinal (I) ALP. Faint staining in the $a_{1}$-globulin position is also seen in track 2 . $A$ daughter (track 4) and son (track 5) show normal total activity and isoenzyme patterns.

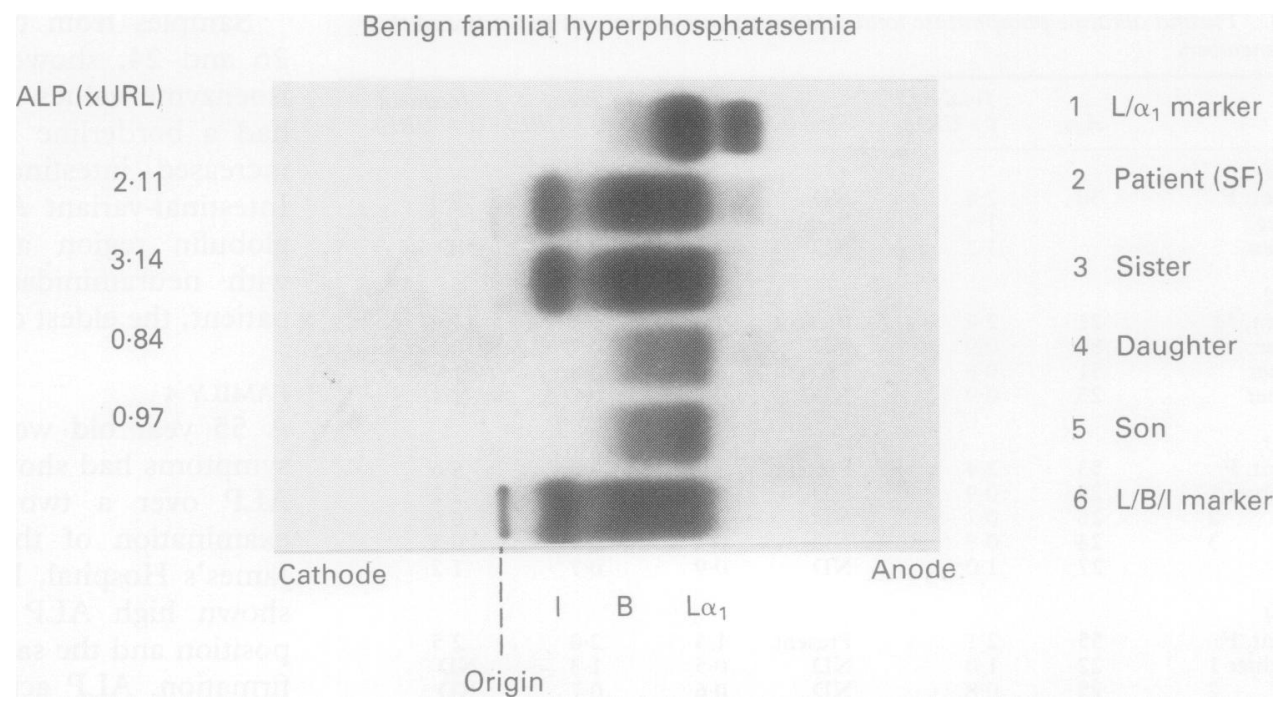

increased total ALP with a borderline increase in bone fraction. Intestinal ALP was present but not raised. The 41 year old sister, however, had total ALP three times the upper reference limit, with a borderline increase in liver but a definite increase in bone and intestinal ALP, the latter accounting for nearly $50 \%$ of total activity. Samples from the sister also showed two faint-staining bands in advance of the liver fraction. Pre-treatment with neuraminidase of this plasma showed intestinal-variant ALP activity, together with persistence of the slow $a_{1}$-band. Plasma from the half-sister showed normal total ALP and isoenzyme fractions (table 1).

\section{Discussion}

Inherited increased ALP in the absence of disease was first reported by Wilson in 1979 in a 15 year old boy. ${ }^{4}$ Total ALP was more than 12 times the upper reference limit and the bone and liver fractions were increased. ALP values two to four times the upper reference limit were also present in the subject's father, paternal grandfather, and two aunts, and on this basis a dominant inheritance pattern was suggested. In 1979, an unusual inherited ALP isoenzyme variant was also reported from the Husavik region of Iceland. ${ }^{9}$ This variant was seen as an additional band of greater electrophoretic mobility than liver ALP, migrating between this fraction and albumin. It was heat stable, uninhibited by phenylalanine, and not retarded by neuraminidase. It was found in 10 out of 343 subjects studied, nine of whom were female and nine of whom were related by common ancestry. All subjects were healthy so an autosomal dominant pattern of inheritance was postulated. In these subjects, however, total ALP was not increased. Since that time several reports of benign familial increase in plasma ALP activity have appeared (table 2), ${ }^{10-25}$ most with an autosomal dominant pattern of inheritance. Such an inheritance pattern has also been observed in a family with concomitant Gilbert's disease. ${ }^{24}$ In this family an autosomal codominant inheritance pattern was considered a more likely explanation for

Table 2 Summary of published reports of index cases of benign inherited hyperphosphatasaemia

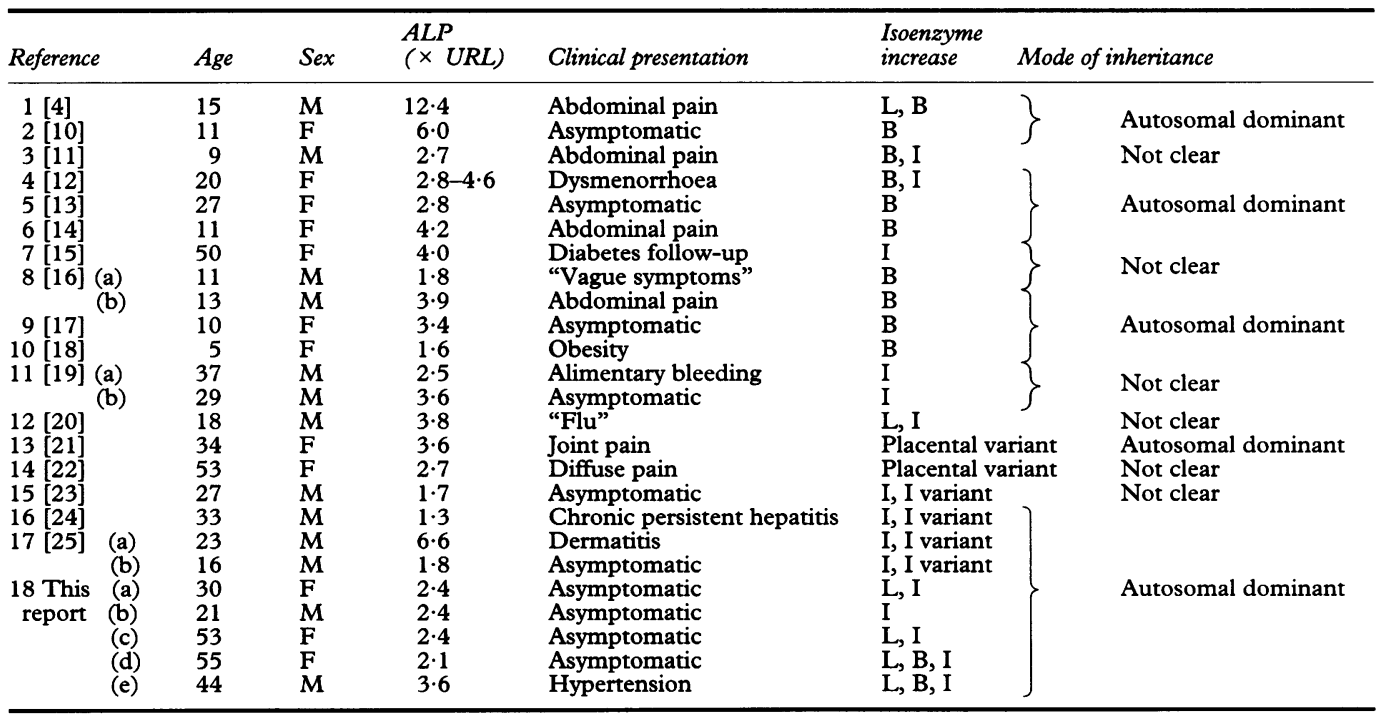

$\mathrm{L}=$ Liver; $\mathrm{B}=$ Bone; $\mathrm{I}=$ Intestinal; $\mathrm{URL}=$ upper reference limit; $\mathrm{F}=$ female; $\mathrm{M}=$ male. 
the presence of the two disorders than genetic linkage.

Inherited increase of either a single isoenzyme fraction-for example, either bone or intestinal ALP, rarely placental-like ALP-or of multiple fractions - for example, liver and bone ALP together or each with intestinal ALP-has been observed (our family 4). ${ }^{20}$ The liver, bone, and kidney forms of ALP are thought to be coded at a single locus (the tissue-non-specific ALP gene) on chromosome 1 , whereas the intestinal and placental are coded at separate loci on chromosome 2. 26-28 Isoenzyme changes may thus represent a change in the products of a single gene (where only a single fraction or liver and bone in combination are increased) or of separate genes (where liver or bone isoenzyme increase is accompanied by raised intestinal ALP). To account for such changes various mechanisms have been proposed, ${ }^{20}$ including mutation affecting gene structure and expression (which would affect individual isoenzymes) or of regulator genes or of genes controlling post-translational modification, or enzyme attachment to or release from cell membranes (which could increase the plasma activity of isoenzymes coded at separate loci).

In non-genetic disorders giving rise to increased intestinal ALP ( $\beta$-globulin mobility) in plasma, the accompanying presence of socalled "intestinal-variant" (hydrophobic) ALP can frequently be shown, this fraction resulting from release of intestinal ALP into the circulation with attached membrane binding domain. ${ }^{78}$ Intestinal-variant ALP in plasma has been reported in familial hyperphosphatasaemia ${ }^{23-25}$ and accompanied an increase in intestinal ALP in various members of three of our five families. We have also noticed a staining band in advance of liver ALP (of slow $a_{1}$-mobility) and retarded by anti-intestinal antibody in members of each of the families we studied. The relevance of this intestinal-like ALP is uncertain.

Where a persistent increase in ALP is accompanied only by an increase in the liver or bone fractions, consideration of a possible genetic abnormality is likely to be much delayed while an extensive search for liver or bone disease is carried out. Where a raised intestinal fraction is observed, however, a genetic disorder may be more readily suspected because the other disorders associated with such increases are few and generally obvious. An inherited cause should be particularly suspected when the intestinal fraction is concomitantly accompanied by an increase in the liver and bone fractions. A persistent increase in intestinal ALP without obvious clinical explanation has, however, also been reported in individuals in whom family studies have failed to show any evidence of heritability. $29-31$

After coming across five examples within 18 months, we suggest that inherited increase in ALP activity deserves wider recognition as a cause of hyperphosphatasaemia, especially in the absence of overt disease, and should be particularly suspected when the intestinal fraction is increased.

We thank Drs D Donaldson, R B Payne, and J Went for specimens referred. Thanks are also due to Dr $T$ Kuwana for the imens referred. Thanks are also due to

1 Fishman WH, Inglis NI, Krant MJ. Serum alkaline phosphatase of intestinal origin in patients with cancer and with cirrhosis of the liver. Clin Chim Acta 1965;12: with cirrh $298-313$.

2 de Broe ME, Bosteels V, Wieme RJ. Increased intestinal alkaline phosphatase in serum of patients on maintenance haemodialysis. Lancet 1974; i:753-4.

3 Skillen AW, Harrison J, Worth RD. Serum alkaline phosphatase of the intestinal type in patients with diabetes Lab f Res Lab Med 1982;9:73-5.

4 Wilson JW. inherited elevation of alkaline phosphatase activity in the absence of disease. $N$ Engl $F$ Med 1979; 301:983-4.

5 Tietz NW, Rinker AD, Shaw LM. IFCC methods for the measurement of catalytic concentrations of enzyme. Part 5. IFCC method for alkaline phosphatase (orthophosphoric monoester phosphohydrolase, alkaline optiphosphoric monoester phosphohydrolase, alkaline optimum, $731-48$

6 Rosalki SB, Foo AY. Two new methods for separating and quantifying bone and liver alkaline phosphatase isoenzymes in plasma. Clin Chem 1984;30:1 182-6.

7 Van Hoof VO, Lepoutre LG, Hoylaerts MF, Chevigne $R$ de Broe ME. Improved agarose electrophoretic method for separating alkaline phosphatase isoenzymes in serum. Clin Chem 1988;34:1857-62.

8 Kuwana T, Rosalki SB. Intestinal variant alkaline phosphatase in plasma in disease. Clin Chem 1990;36: phatase in

9 Hosenfeld D, Lehmann W, Palsson J, Frank R. A rare electrophoretic variant of serum alkaline phosphatase in electrophoretic variant of serum alkaline phosphatase

10 Parker PH, Ghishan FK. Asymptomatic familial elevation of serum alkaline phosphatase levels. Am $\mathcal{F}$ Dis Child 1980;134:1094-5

11 McEvoy M, Skrabanek P, Wright E, Powell D, McDonagh B. Family with raised serum alkaline phosphatase in the absence of disease. Br Med $\mathcal{F} 1981 ; 282$. 1272 .

12 Ducobu J, Dupont P. Inherited raised alkaline phosphatase in the absence of disease. Lancet 1981;i:1372-3.

13 Nogueros LC, Lleida JV, Badia MS, et al. Raised serum alkaline phosphatase activity in one family. Arch Intern Med 1982;142:188-9.

14 Kruse K. Inherited isolated hyperphosphatasemia. Acto Paediatr Scand 1983;72:833-5.

15 Rapado A, Esbrit P. Hiperfosfatasia asintomatica familiar por elevacion de la isoenzyme intestinal. Revista Clinica Española 1984;173:53-4.

16 Abassi V, Colon AR, Schwartz RH. Benign elevation of serum alkaline phosphatase, transient and persisten variety. Clin Paediatr 1984;23:336-7.

17 Kruse K. Normal bone turnover in isolated hyperphosphatasemia. f Paediatr 1985;106:946-8.

18 Lewes JM. Persistent isolated hyperphosphatasemia. South Med f 1987;80:788-90.

19 Rico H, Martinez F, Romero P, Casimiro C. Hiperfosfatasemia familiar benigna: a prosposito de un observacion. Revista Clinica Española 1987;180:465-6.

20 Siraganian PA, Mulvihill JJ, Mulivor RA, Miller RW. Benign familial hyperphosphatasemia. $\mathscr{F} A M A$ 1989;261 1310-2.

21 Onica D, Rosendahl K, Waldenlind L. Inherited occurrence of a heat stable alkaline phosphatase in the absence of malignant disease. Clin Chim Acta 1989;180 23-34.

22 Onica D, Rosendahl K, Waldenlind L. Further characterisation of a heat-stable alkaline phosphatase with low sensitivity to L-phenylalanine Clin Chim Acta 1990;194: 193-202.

23 McLachlan R, Callaghan S. An inherited variant alkaline phosphatase. Clin Chem 1990;36:1126.

24 Lieverse AG, van Essen GG, Beukeveld GJJ, et al. Familial increased serum intestinal alkaline phosphatase: a new variant associated with Gilbert's syndrome. $f$ Clin Pathol 1990;43:125-8.

25 Panteghini M. Benign inherited hyperphosphatasemia of intestinal origin. Report of two cases and a brief review of the literature. Clin Chem 1991;37:1449-52.

26 Swallow DM, Povey S, Parker M, et al. Mapping of the gene coding for the human liver/bone/kidney alkaline phosphatase to chromosome 1. Ann Hum Genet 1986; 50:229-35.

27 Henthorn PS, Raducha M, Kadesch T, Weiss MJ, Harris $H$. Sequence and characterisation of the human intestinal alkaline phosphatase gene. $f$ Biol Chem $1988 ; 263$ : nal alkaline $12011-9$.

28 Martin D, Tucker DF, Gorman P, Sheer D, Spurr NK Trowsdale J. The human placental alkaline phosphatase gene and related sequences map to chromosome 2 band q37. Ann Hum Genet 1987;51:145-52.

29 Bentouati L, Baboli MS, Hachem H, Hamza M, Canal P Soula G. Hyperphosphatasemia related to three intestinal alkaline phosphatase isoforms: biochemical study. Clin Chim Acta 1990;193:93-102.

30 Kricka LJ, Wilding P, Long WB, Mulivor RA. Benign hyperphosphatasemia. Clin Chem 1990;36:389.

31 Rodriguez-Garcia JL, Fraile G. Benign non-inherited hyperphosphatasemia. Eur f Intern Med 1991;2:121-2. 